\title{
Result Analysis Using Classification Techniques
}

\author{
Varsha Namdeo
}

Anju Singh

Divakar Singh

Dr. R.C Jain

\begin{abstract}
Data Mining is a powerful tool for academic intervention. The educational institutions can use classification for comprehensive analysis of students' characteristics. In our work, we collected student's data from engineering course. And then apply four different classification methods for classifying students based on their Final Grade obtained in their Courses. We compare these algorithms of classification and check which algorithm is optimal for classifying students' based on their final grade.

By this task we extract knowledge that describes students' performance in end semester examination. This work will help to the institute to improve the performance of the students.

The full text of the article is not available in the cache. Kindly refer the IJCA digital library at www.ijcaonline.org for the complete article. In case, you face problems while downloading the full-text, please send a mail to editor at editor@ijcaonline.org
\end{abstract}

